\title{
The use of cloprostenol to reduce the diestral phase of the sexual cycle of mares
}

\author{
Elena Solodova* \\ All-Russian Research Institute for Horse Breeding, p / o Institute of horse breeding, Rybnoe district, \\ Ryazan region, Russia
}

\begin{abstract}
The article presents the results of the analysis of the pregnancy rates of mares depending on the duration of the intervals from cloprostenol preparation injection to ovulation. It was found that with a decrease in the interval ( $\leq 7$ days), the pregnancy rate decreases by $30 \%(\mathrm{p} \leq 0.05)$. To determine the optimal time for cloprostenol use, an analysis of the intervals from injection to ovulation was performed, depending on the day of the sexual cycle and the largest follicle diameter. The average intervals before ovulation in the groups, depending on the day of injection $(5,6-7,8-10$, $11-15$ days), have a duration from $8.5 \pm 0.4$ to $11.1 \pm 0.5$ days. However, it is difficult to predict the time of ovulation, since the duration of the interval from cloprostenol treatment to ovulation varies greatly, the difference in the extreme values in the groups can be from 8 to 13 days. More precisely, it is possible to predict the duration of the interval until the follicle reaches $35 \mathrm{~mm}$ with a known diameter of the largest follicle at the time of injection. In this way, in the group with the diameter of the largest follicle $\leq 22 \mathrm{~mm}$, this interval is $7.13 \pm 0.17$ days, from 23 to $26 \mathrm{~mm}-4.59 \pm 0.16$ days, from 27 to $30 \mathrm{~mm}-2.91 \pm 0.13$ days. The difference in the duration of the intervals before ovulation in these groups is more significant - from 5 to 11 days and depends on the individual duration of the mare estrus.
\end{abstract}

\section{Introduction}

One of the main factors contributing to the achievement of high results of the breeding company on breeding farms and stud farms is the competent use of hormonal preparations to regulate the processes occurring in the reproductive system of mares. As a rule, they are used to shorten the diestral phase of the cycle during sexual cyclicity, interrupt prolonged diestrus, synchronize the cycles of donor mares and embryo recipients, and enhance intrauterine clearance in the treatment of endometritis [1]. The reduction of the diestral period and, accordingly, the interovulatory intervals is the most common method of manipulating the duration of the estrus cycle of mares. Currently, synthetic analogues of prostaglandin PGF2a - cloprostenol and dinoprost - are widely used for these purposes. The mechanism of their action is based on the interruption of the corpus luteum functioning (luteolysis) and the induction of prolonged low-amplitude uterus contractions [2, 3].

Due to the high affinity of the cell membrane of luteal cells of the corpus luteum to

\footnotetext{
* Corresponding author: 1.solodowa2012@yandex.ru
} 
PGF2a and slow metabolic clearance, mares are about five times more sensitive to the luteolytic effect of exogenous prostaglandin PGF2a than cattle and sheep [4]. In addition, the use of prostaglandin PGF2a analogs can cause significant side effects. Mares may experience increased sweating, tachycardia, diarrhea, and colic symptoms. The strength and duration of side effects are individual and depend on the dose. As a rule, they subside within one to five hours after PGF2a administration [5, 6]. Among the side effects of PGF2a effect on the reproductive sphere, the following are noted: acceleration of follicle development and ovulation, increase in polyovulations and a decrease in pregnancy rate $[6$, 7]. Therefore, reducing the doses used and timely use of preparations is of great practical importance.

The interval from PGF2a-induced luteolysis to ovulation is very variable and when preparations are injected 5-6 days after ovulation, it occurs on average after 9.5 days with a range from 1 to 15 days $[8,9]$. The large difference in the interval length mainly depends on the diameter of the largest follicle present in the ovary at the time of PGF2a application. The interval decreases as the size of the follicle increases. The PGF2a effect also depends on the dose and frequency of treatments [10].

It is established that during the estrous cycle, the development of one or two follicular waves can be observed. In mares with one follicular (primary) wave, the future ovulatory follicle occurs in the period from the middle to the end of the diestrus. The secondary follicular wave often occurs close to the previous ovulation and causes the development of early diestral follicles, which can reach $40 \mathrm{~mm}$ in diameter. Further, they regress or luteinize, giving way to a new primary follicular wave. In some cases, despite the high concentration of progesterone, diestral follicles originating from the secondary wave can ovulate (diestral ovulation) [11]. In mares with one or two follicular waves, there are no differences in the length of the interovulatory intervals. However, if ovulation of the diestral follicle occurs, the interovulatory interval is lengthened. In this way, some mares may have follicles less than $20 \mathrm{~mm}$ in size in the middle of the diestrus, while others may have follicles over $40 \mathrm{~mm}$ in size.

Sometimes the corpus luteum is preserved in mares, prolonging the luteal phase from 20 to 80 days. Prolonged diestrus (more than 16 days after ovulation) due to the presence of a permanent corpus luteum may occur in mares due to: 1) inability of the endometrium to release PGF2a, 2) embryonic loss after maternal recognition of pregnancy, 3) ovulation of the diestral follicle shortly before luteolysis of the primary corpus luteum. The use of the recommended dose of PGF2a (dinoprost or cloprostenol) will cause luteolysis and the mare coming in season [1].

In this way, the corpus luteum plays a key role in the regulation of the estrous cycle. Undergoing rapid cellular and vascular changes, it becomes one of the most vascularized formations in the body. Ultrasound studies show that the degree of echogenicity of the corpus luteum varies depending on the period of its development [12]. A gradual increase in progesterone concentration, characteristic of early diestrus, correlates with an increase in the diameter and a decrease in the echogenicity of the corpus luteum. Regression of the corpus luteum (natural and PGF-induced) and a decrease in progesterone concentration correspond to a decrease in the size of the corpus luteum and an increase in its echogenicity $[1,13]$. Detection and assessment of the corpus luteum structure during ultrasound examination is important for reasonable decision-making on the use of PGF2a preparations.

In Russia, cloprostenol preparations have received the greatest use, which, compared with dinoprost preparations, have fewer side effects and are characterized by a longer halflife. These drugs can include two isomers: D-cloprostenol (has luteolytic activity) and Lcloprostenol (does not have luteolytic activity, but reacts with receptors of the corpus luteum, thereby reducing the likelihood of D-cloprostenol molecules interaction with them). That is why in practice it is advisable to use drugs containing mainly active prostaglandin 
isomers. In Russia, as a rule, preparations of domestic production are used: magestrofan containing racemic (equimolar, in equal quantities) mixture of $\mathrm{D}$, L-cloprostenol and estrofanthin (an analog of D-cloprostenol). The recommended by the manufacturer dose of these preparations is $250 \mathrm{mcg}(1 \mathrm{ml})$ per mare [1].

Purposes and tasks of research: To predict the level of pregnancy in cycles with artificially induced luteolysis, the task was set to analyze the length of the intervals from cloprostenol injection to ovulation, depending on the day of the cycle and the size of the largest follicle present in the ovaries at the time of injection, to establish a relationship between pregnancy rates and the duration of these intervals.

\section{Material and methods of research}

To analyze the pregnancy rates, depending on the length of the interval between treatment and ovulation, a retrospective analysis of the pregnancy rates of mares who were treated with cloprostenol preparations was performed. The data were collected on the breeding stock of the stud farms of LLC "Stud Farm "Lokotskoy" and LLC "Lag-Service Agro" from 2013 to 2021. For the analysis of pregnancy rates, the mares were divided into groups: group 1 - the length of the interval from injection to ovulation is $\leq 7$ days $(n=35)$, group 2 8-10 days $(n=58)$, group $3-\geq 11$ days $(n=39)$. Since the effectiveness of insemination of mares is influenced by quite a lot of factors, the following cycles were excluded from the treatments: cycles from problem mares with reduced fertility, cycles in which fresh or frozen-thawed seed of poor quality was used (less than $500 \times 10^{6}$ mobile spermatozoids in a dose).

To determine the optimal period for cloprostenol injection at a known cycle day and a mature corpum luteum (more than 5 days after ovulation) we analyzed the duration of the intervals between treatment with cloprostenol and ovulation, as well as the duration of cycles depending on the day of the cycle on which the injection was performed. All cycles were assigned to one of four groups: 1) injection on the 5th day of the cycle; 2) on the 6-7 day of the cycle; 3 ) on the 8-10 day; 4) on the 11-15 day.

To analyze the duration of the interval from cloprostenol injection before ovulation, depending on the diameter of the largest follicle at the time of injection of all cases of artificial reductions diestral period were assigned to one of 4 groups: group $1(n=70)$ diameter of the largest follicle - $\leq 22 \mathrm{~mm}$, group $2(\mathrm{n}=49)$ - from 23 to $26 \mathrm{~mm}$, group $3(\mathrm{n}=$ 39 ) - from 27 to $30 \mathrm{~mm}, 4$ group $(\mathrm{n}=24)$ - from 31 to $38 \mathrm{~mm}$. Mares of groups 1, 2, 3 were given intramuscular injections of cloprostenol preparations in doses from 0.6 to $1.0 \mathrm{ml}$, mares of group $4-0.2-0.3 \mathrm{ml}$ intramuscularly. The treatment included cycles with the use of cloprostenol from the 5th to the 13th day of diestrus, cycles with prolonged diestrus (more than 16 days), as well as with an unknown day of previous ovulation, if the corpus luteum was detected during ultrasound examination, and the uterus during rectal and ultrasound examination corresponded to the in diestrus state. Mares that did not show a clinical response (the onset of uterine edema and the release of a leading follicle that reached a diameter of 32-35 mm) within 10 days after injection were excluded from treatment. Two parameters were compared between the groups: length of the interval from injection until the follicle reaches an average diameter of $35 \mathrm{~mm}$, and length of the interval from injection to ovulation. The average diameter of the follicle was determined by ultrasound examination of both ovaries by dividing by two the sum of the largest diameters of the follicle vertically and horizontally.

To interrupt the diestral period, domestic preparations of cloprostenol were used: magestrofan (CJSC Mosagrogen, Russia) - in doses from 0.3 to $1 \mathrm{ml}$ or estrofanthin in doses of 0.2-0.6 ml (LLC NPC Ascont+, Russia) intramuscularly. 
All the work on the ultrasound examination of mares and their insemination was carried out by the author of this study. The feeding and maintenance of mares in these farms corresponded to the established zootechnical standards. Ultrasound examinations were performed on the Mindrey DP-50 device. The data were processed according to the generally accepted method of calculating statistical characteristics, evaluating the statistical significance between groups using the Student-Fisher criterion.

\section{Results of the study and discussion}

The analysis of the pregnancy rates in mares, depending on the duration of the interval between treatment with cloprostenol and ovulation, showed a reduced (by 30\%) level of pregnancy rates in the group with an interval of 7 days or less.

Table 1 Pregnancy rates in mares depending on the length of the interval between injection and ovulation.

\begin{tabular}{|c|c|c|c|}
\hline \multirow{2}{*}{ Indicators } & \multicolumn{3}{|c|}{ Length of intervals (days) } \\
\cline { 2 - 4 } & $\leq 7$ & $8-10$ & $\geq 11$ \\
\hline Total inseminated & 35 & 58 & 39 \\
\hline Became pregnant, $\mathrm{n}$ & 19 & 43 & 30 \\
\hline$\%$ & $54 \pm 8.4^{\mathrm{a}}$ & $74 \pm 5.8^{\mathrm{b}}$ & $76 \pm 6.8^{\mathrm{d}}$ \\
\hline
\end{tabular}

$\mathrm{p}^{\mathrm{ab}} \leq 0.05 ; \mathrm{p}^{\mathrm{ad}} \leq 0.05$

It is obvious that a short interval in most cases corresponds to a shortened estrus, which causes a reduced pregnancy rate in this group. The results obtained are consistent with the previous results of our studies of the pregnancy rate level in cycles with short estrus [14] and similar studies by Juan Cuervo-Arango Lecina [8].

Table 2. Duration of intervals between treatment with cloprostenol and ovulation, depending on the day of injection.

\begin{tabular}{|c|c|c|c|c|c|c|}
\hline $\begin{array}{c}\text { Grou } \\
\text { p No. }\end{array}$ & $\begin{array}{c}\text { Day of } \\
\text { injection, after } \\
\text { ovulation }\end{array}$ & \multirow{2}{*}{$\begin{array}{c}\mathrm{n}, \\
\text { cycles }\end{array}$} & \multicolumn{2}{|c|}{$\begin{array}{c}\text { Interval from treatment } \\
\text { to ovulation, days }\end{array}$} & \multicolumn{2}{|c|}{$\begin{array}{c}\text { Cycle duration, } \\
\text { days }\end{array}$} \\
\cline { 4 - 7 } & 5 & 37 & $8.5 \pm 0.4$ & $2-15$ & $13.4 \pm 0.4^{\mathrm{e}}$ & $7-19$ \\
\hline 1. & 5 & 24 & $8.8 \pm 0.5^{\mathrm{b}}$ & $6-14$ & $14.9 \pm 0.5^{\mathrm{t}}$ & $12-20$ \\
\hline 2. & $6-7$ & 29 & $11.1 \pm 0.5^{\mathrm{a}}$ & $5-17$ & $19.6 \pm 0.5^{\mathrm{p}}$ & $14-25$ \\
\hline 3. & $8-10$ & 19 & $8.9 \pm 0.6^{\mathrm{d}}$ & $4-12$ & $21.5 \pm 0.6^{\mathrm{m}}$ & $16-26$ \\
\hline 4. & $11-15$ & &
\end{tabular}

$\mathrm{p}^{\mathrm{ab}} \leq 0.001 ; \mathrm{p}^{\mathrm{ad}} \leq 0.01 ; \mathrm{p}^{\text {et }} \leq 0.001 ; \mathrm{p}^{\mathrm{t}} \leq 0.01 ; \mathrm{p}^{\mathrm{pm}} \leq 0.01$.

The table shows that in groups 1, 2 and 4, the average intervals were $8.5 ; 8.8$ and 8.9 days, respectively, and have a significant difference with the average interval of group 3 (11.1 days). However, in $70-90 \%$ of mares in all groups, the difference in the intervals from treatment with cloprostenol to ovulation is from 2 to 5 days. The minimum and maximum values for the rest of the mares differ by 8-13 days. Therefore, it is difficult to give any forecast of the duration of the time interval from injection to ovulation, considering only the day of the cycle on which the injection was made. The difference in the average cycle duration in each group is significant, but in $10-35 \%$ of mares of each group there is a significant variation of this indicator (from 8 to 12 days). The analysis of the table shows that when cloprostenol is injected on 8-10 days, the cycle is slightly reduced, and when injected on 11-15 days, the cycle is not reduced. Therefore, if it is necessary to reduce the cycle, the use of cloprostenol is more justified from the 5th to the 7 th day of the cycle - its reduction is observed on average to 13.4-14.9 days. 
The large variability of intervals in 10-35 \% of mares in each group is explained by the presence of diestral follicles of different sizes in the same cycle period. Therefore, we analyzed the intervals from cloprostenol injection to ovulation, depending on the diameter of the largest follicle present in the ovary at the time of injection.

Table 3. The duration of the intervals between cloprostenol injection and ovulation, depending on the diameter of the largest follicle at the time of treatment.

\begin{tabular}{|c|c|c|c|c|c|c|c|}
\hline \multirow{3}{*}{$\begin{array}{c}\text { Gr } \\
\text { oup } \\
\text { No. }\end{array}$} & \multirow{3}{*}{$\begin{array}{l}\text { Follicle } \\
\text { diameter, } \\
\mathrm{mm}\end{array}$} & \multirow{3}{*}{$\begin{array}{c}\mathrm{n}, \\
\text { cycle } \\
\mathrm{s}\end{array}$} & \multirow[t]{3}{*}{ Dose, $\mathrm{ml}$} & \multicolumn{4}{|c|}{ Interval from treatment to the follicle } \\
\hline & & & & \multicolumn{2}{|c|}{$35 \mathrm{~mm}$, days } & \multicolumn{2}{|c|}{ Ovulation, days } \\
\hline & & & & $\mathrm{M} \pm \mathrm{m}$ & $\min -\max$ & $\mathrm{M} \pm \mathrm{m}$ & $\min -\max$ \\
\hline 1. & $\leq 22$ & 70 & $0.6-1.0$ & $7.13 \pm 0.17$ & $5-10$ & $11.3 \pm 0.29$ & $7-18$ \\
\hline 2. & $23-26$ & 49 & $0.6-1.0$ & $4.59 \pm 0.16$ & $3-8$ & $8.57 \pm 0.21$ & $6-13$ \\
\hline 3. & $27-30$ & 34 & $0.6-1.0$ & $2.91 \pm 0.13$ & $2-4$ & $6.88 \pm 0.21$ & $4-9$ \\
\hline 4. & $31-38$ & 24 & $0.2-0.3$ & $1.42 \pm 0.21^{*}$ & $0-1$ & $4.25 \pm 0.35$ & $2-8$ \\
\hline
\end{tabular}

* - the interval is indicated for follicles that have not reached $35 \mathrm{~mm}$ at the time of injection.

The table shows that the average intervals at which it is possible to get pregnancy rate of $74-76 \%$ can be predicted in groups 1 and 2, when at the time of injection in the ovaries the largest follicle does not exceed $26 \mathrm{~mm}$ in diameter. However, in 20-27\% of mares within groups 1 and 2, there is a significant variation (from 7 to 11 days) in the duration of the intervals from treatment to ovulation. This is probably due to the difference in the diameter of the largest follicle within the group at the time of injection, the degree of maturity of the corpus luteum, as well as the estrus duration. The conclusion that there is a significant difference in the duration of estrus within the groups can be made based on the smaller difference in the duration of the intervals from treatment to reaching $35 \mathrm{~mm}$ in diameter by the largest follicle.

The average intervals in groups 3 and 4 correspond to the reduced level of pregnancy rate established in this study. However, in the third group, in $67.6 \%$ of mares, the duration of the intervals from the follicle reaching $35 \mathrm{~mm}$ to ovulation was 4-5 days. In our previous studies [17], it was found that with the duration of the estrous period of 4 or more days in cycles with the use of cloprostenol, the level of pregnancy is high. 5 mares $(14.7 \%)$ with regression or luteinization of the leading follicles were excluded from the treatment. Therefore, the probability of such a development of events should be considered with a follicle diameter of $27-30 \mathrm{~mm}$.

The results of our studies have shown the effectiveness of small doses of cloprostenol $(0.2-0.3 \mathrm{ml})$ when injected in the presence of large (more than $31 \mathrm{~mm}$ ) diestral follicles. The average interval before ovulation in group 4 was $4.25 \pm 0.35$ days. Only 11 out of 24 mares ovulated after 5-8 days. If we consider that a single administration of PGF2a reduces the level of progesterone in the blood to a basal value in 48 hours [16], then this small group of mares has time (3-6 days) for the normal course of the estrous phase of the cycle. In the rest mares (13 out of 24) of this group, the interval duration was from 2 to 4 days, and ovulation of the follicles was not preceded by the appearance of behavioral signs of estrus, uterine edema, or they were very weak. And although such mares were not inseminated, the results of S. Sánchez's, et.al research [15] allow to predict the absence or extremely low pregnancy rate, when inseminating mares with absent or short-term uterine edema during estrus. 


\section{Conclusion}

The results of this study allow to draw the following conclusions:

1. The level of pregnancy in mares with the duration of the interval from cloprostenol injection to ovulation for 8 or more days is $74-76 \%$. When the interval is reduced ( $\leq 7$ days), this indicator decreases by $30 \%$.

2. The analysis of the duration of the intervals from treatment to ovulation, depending on the day of injection, showed that the average interval in the groups is from 8.5 to 11.1 days. Nevertheless, it is difficult to predict the time of ovulation, since the duration of the period from treatment with cloprostenol to ovulation varies greatly.

3. More precisely, it is possible to predict the duration of the interval until the follicle reaches $35 \mathrm{~mm}$ in diameter with a known diameter of the largest follicle at the time of injection. The interval to ovulation depends on the individual duration of estrus in the mare. 4. The results of our studies have shown the effectiveness of small doses of cloprostenol (0.2-0.3 $\mathrm{ml}$ or $50-75 \mathrm{mcg}$ per head) when injected in the presence of large (more than 31 $\mathrm{mm}$ ) diestral follicles.

5. To achieve high pregnancy rate, the most optimal injection time for cloprostenol is an injection in the presence of the largest follicle in the ovaries, which diameter is equal to or less than $26 \mathrm{~mm}$.

\section{References}

1. E.V. Solodova, J. Hippology and Veterinary Medicine 2 (36), 93-99 (2020)

2. R.H. Douglas \& O.J. Ginther, J. Prostaglandins 2, 265-68 (1972)

3. E. A. Coffman \& C.R. Pinto, J. Equine Veterinary Science 40, 34-40 (2016)

4. H.K. Shrestha, M.A. Beg, R.R. Burnette, O.J. Ginther, Biolody of reproduction, 87(1), $18,1-6(2012)$

5. O.J. Ginther, M.A. R. Siddiqui, M.A. Beg, J. Theriogenology 72, 417-724 (2009)

6. J. Cuervo-Arango, The effect of cloprostenol on follicular development, ovulation, anovulation and pregnancy rate in the mare, (Helsinki, Finland: Department of Production Animal Medicine Faculty of Veterinary Medicine University of Helsinki, 2010)

7. J. Cuervo-Arango, J.R. Newcombe, J. Theriogenology 72, 1262-67 (2009)

8. J. C. Samper, J. Theriogenology 70, 445-47 (2008)

9. J. C. Samper, H. Geertsema, P. Hearn, Rate of luteolysis, folliculogenesis and interval to ovulation of mares treated with a prostaglandin analogue on d 6 or 10 of the estrous cycle. In: Proceedings of the Annual Convention of the American Association of Equine Practitioners, 169-71 (1993)

10. C. Barker, K. Echeverria, D. Morell, C.S. Whisnant, C.R.F. Pinto, J. Anim. Reprod. Sci. 94, 207-9 (2006)

11. T. Raz, T. Aharonson-Ras, Israel Journal of Veterinary Medicine 67(1), 11-18 (2012)

12. G. Ferreira-Dias, P.P. Bravo, L. Mateus, D.A. Redmer, J.A. Medeiros, Domestic Animal Endocrinology 30(4), 247-59 (2006).

13. L.F. Lebedeva, E.V. Solodova, J.Horse breeding and equestrian sports 3, 11-15 (2020)

14. S. Mateu-Sánchez, J.R. Newcombe, C. Garcés-Narro, J. Cuervo-Arango, J. Theriogenology 86(6), 1506-15, (2016)

15. J.R. Bergfelt, R.A. Pierson, O.J. Ginther, Theriogenology, 65, 1605-19 (2006) 
16. E.V. Solodova, J.Horse breeding and equestrian sports 1, 20-23 (2019) 